\title{
Elastic Properties of Natural Sea Surface Films Incorporated with Solid Dust Particles: Model Baltic Sea Studies
}

\author{
Adriana Z. Mazurek ${ }^{1}$ and Stanisław J. Pogorzelski ${ }^{2}$ \\ ${ }^{1}$ Department of Physics, Warsaw University of Life Sciences, Nowoursynowska 159, 02-776 Warsaw, Poland \\ ${ }^{2}$ Institute of Experimental Physics, University of Gdansk, Wita Stwosza 57, 80-952 Gdańsk, Poland
}

Correspondence should be addressed to Stanisław J. Pogorzelski, fizsp@ug.edu.pl

Received 3 August 2012; Accepted 8 October 2012

Academic Editor: Robert Frouin

Copyright (C 2012 A. Z. Mazurek and S. J. Pogorzelski. This is an open access article distributed under the Creative Commons Attribution License, which permits unrestricted use, distribution, and reproduction in any medium, provided the original work is properly cited.

\begin{abstract}
Floating dust-originated solid particles at air-water interfaces will interact with one another and disturb the smoothness of such a composite surface affecting its dilational elasticity. To quantify the effect, surface pressure ( $\Pi$ ) versus film area $(A)$ isotherm, and stress-relaxation ( $\Pi$-time) measurements were performed for monoparticulate layers of the model hydrophobic material (of $\mu \mathrm{m}$ diameter and differentiated hydrophobicity corresponding to the water contact angles (CA) ranging from 60 to $140^{\circ}$ ) deposited at surfaces of surfactant-containing original seawater and were studied with a Langmuir trough system. The composite surface dilational modulus predicted from the theoretical approach, in which natural dust load signatures (particle number flux, daily deposition rate, and diameter spectra) originated from in situ field studies performed along Baltic Sea near-shore line stations, agreed well with the direct experimentally derived data. The presence of seawater surfactants affected wettability of the solid material which was evaluated with different CA techniques applicable to powdered samples. Surface energetics of the particlesubphase interactions was expressed in terms of the particle removal energy, contact cross-sectional areas, collapse energies, and so forth. The hydrophobic particles incorporation at a sea surface film structure increased the elasticity modulus by a factor $K$ $(1.29-1.58)$. The particle-covered seawater revealed a viscoelastic behavior with the characteristic relaxation times ranging from 2.6 to $68.5 \mathrm{sec}$.
\end{abstract}

\section{Introduction}

The atmospheric transport and deposition of mineral particles strongly influence the physics and chemistry of the marine atmosphere, and the biogeochemical cycles in seawater. So far, our emphasis has been closed on the multicomponent character of natural surfactant films, and the consequent complexities involved in any attempt to predict the interfacial viscoelastic properties playing a crucial role in modeling of physical systems with surface film-mediated interfaces. A variation in the surface rheological parameters of the natural surfactant seawater films has been conceived as a different in source of surfactant materials and in physical dynamics reflecting organic matter migration, degradation, and spatial-temporal dynamics in natural waters [1]. In nearly all cases, uniform, homogeneous surfaces have been studied. However, in "real" systems, in technology, biology, and oceanography, surfaces are very often non-uniform. For instance, a flat surface containing a surfactant monolayer which has undergone a two-dimensional phase separation falls under this definition, as well as air-water and oil-water interfaces with droplets, solid particles, or even thin layers of a microemulsion, foam, or a bicontinuous phase. The composite surfaces seem to be homogeneous by macroscopic observation but heterogeneous at a microscopic level. Monoparticulate layers of fine solid particles at air-water interfaces, like the monomolecular films of insoluble surfactants, can be formed by spreading from volatile organic dispersions or scattering onto the water surface. In such a definition, a composite surface consists of a mosaic of different surfaces leading to physicochemical or geometrical roughness. The exhibited film parameters variability with the environmental factors (film temperature, ionic strength, and $\mathrm{pH}$ of the aqueous subphase, wind speed, and time scale of relaxation processes taking place in a multicomponent natural film) has been already discussed in detail elsewhere $[1,2]$. 
In this paper, for the first time, the influence of mineral dust particles (of micrometer diameters) deposition at the natural seawater interfaces on the surface dilational viscoelasticity was addressed. In the subsequent sections a general approach for the treatment of the dynamic properties of the composite surfaces is proposed and further quantified on several natural environment interfacial systems.

The composite surface has the particular surface rheological properties dependent not only on the particle number flux, particle shape, and its dimension but also on the wettability of solid material in contact with seawater [3]. The contact angle (CA) is a common measure of the hydrophobicity of a solid surface. Such particulate monolayers have been shown to possess the compression characteristics that are similar to insoluble monomolecular monolayers [4] and have been found to be capable of stabilizing foams and emulsions [5]. However, the interpretation of the observed contact angle is complicated by many factors such as the physical and chemical heterogeneity of the system, smoothness of the surface, presence of surfactants (autophobing affect), which all can affect the measured value. The range of contact angles of natural solid particles in seawater is not known, although more typically natural particles are characterized by contact angles of less than $90^{\circ}$ (being of hydrophilic solid material). The input data for the model studies were derived from the supplementary field measurements of several natural environmental systems quantified in terms of the natural dust load signatures (the particle number flux, daily deposition rate, particle shape, and its diameter spectra) registered in several sampling stations located nearby sea shore (Gulf of Gdańsk, Baltic Sea, Poland). The aim of the paper was to quantify the natural dry aerosol particles effect on the dilational viscoelasticity of the apparent seawater surface.

\section{Theoretical Background}

2.1. Surface Dilational Viscoelasticity. The dilational elasticity modulus $E_{\text {isoth }}$ (or Gibb's modulus), expressing the static, compressional response of a film to the surface compression or dilation corresponding to isotherm registration in its thermodynamic equilibrium, is defined as [8]

$$
E_{\text {isoth }}=-A\left(\frac{d \Pi}{d A}\right),
$$

where $\Pi$ is the surface pressure of a film, and $A$ is the film area.

The establishment of thermodynamic equilibrium in the film is not trivial since the most real surfactant interfacial systems are viscoelastic. The effect depends on the dimensionless parameter Deborah number (De) defined as the ratio of the film relaxation time $\tau$ to the "time of observation" (a reciprocal of the strain rate of a film: $t_{\mathrm{obs}}=[(d A / A) / d t]^{-1}$, as argued in [9]). The interfacial system appears to be at the quasi-equilibrium thermodynamic state if De number is less than unity.

Any relaxation process in films leads to dilational viscoelasticity, and the surface dilational viscoelastic modulus $E$ is a complex quantity composed of real $E_{d}$ (dilational elasticity) and imaginary $E_{i}\left(=\omega \eta_{d}\right.$, where $\eta_{d}$ is the dilational viscosity) parts $E=E_{d}+i E_{i}=E_{o} \cos \varphi+i E_{o} \sin \varphi$, where $\omega$ is the angular frequency of periodic oscillations, $E_{o}=$ $-\Delta \Pi /(\Delta A / A)$ represents the amplitude ratio between the surface stress and strain, and $\varphi$ is the loss angle of the modulus [10]. For surface layers exhibiting a pure elastic behavior the linear relation between $\Delta \Pi$ and $\Delta A$ appears, as shown by (1). In the case of the viscoelastic film, the relation contains an additional term depending on the surface deformation rate:

$$
\Delta \Pi=E_{\text {isoth }} \frac{\Delta A}{A}+\eta_{d} \frac{d(\Delta A / A)}{d t} .
$$

The time scale of the relaxation processes taking place in surface films, and the viscoelasticity modulus parts can be derived from the stress-relaxation studies [11]. The surface pressure-time $(\Pi-t)$ response of a film to a rapid step $(\Delta t=$ $0.2-1.5 \mathrm{~s})$ relative surface area deformation $\Delta A / A_{o}(=0.07-$ 0.23 ) is registered and presented in the following form [12]:

$$
\ln \left[\frac{\left(\Pi_{\infty}-\Pi_{t}\right)}{\left(\Pi_{\infty}-\Pi_{o}\right)}\right]=-\lambda_{i} t
$$

where $\Pi_{\infty}, \Pi_{o}$, and $\Pi_{t}$ are the surface pressures at steadystate condition $(t \rightarrow \infty)$, at time $t=0$, and at any time $t ; \lambda_{i}$ is the fist-order rate constant related to the relaxation time $\tau_{i}$ $\left(=1 / \lambda_{i}\right)$.

In the framework of a model for dilational viscoelasticity, adapted to the stepwise deformation mode, the real and imaginary parts of $E$ can be obtained from the following relations [13]:

$$
\begin{gathered}
E_{d}=E_{o}\left[\frac{(1+\Omega)}{\left(1+2 \Omega+2 \Omega^{2}\right)}\right], \\
E_{i}=E_{o}\left[\frac{\Omega}{\left(1+2 \Omega+2 \Omega^{2}\right)}\right] \\
E_{o}=\frac{\left(\Pi_{o}-\Pi_{\infty}\right)}{\left(\Delta A / A_{o}\right)} \text { is an amplitude of the modulus } E \\
\text { where } \Omega=\left(\frac{\Delta t}{\tau_{i}}\right)^{1 / 2}, \quad \tan \varphi=\frac{\Omega}{(1+\Omega)} . \\
|E|=\left(E_{d}^{2}+E_{i}^{2}\right)^{1 / 2} \text { is the modulus of the complex quantity } E ;
\end{gathered}
$$

$\Delta t$ is the applied step film area deformation time.

At sufficiently low film area compression rates (De $\ll 1)$, the dilational viscoelasticity modulus can be approximated by $E_{\text {isoth. }}$.

2.2. Structural Parameters of Solid Particle Layers at the Air-Water Interface. The data collected in the surface film elasticity measurements performed on the model particleincorporated inhomogeneous films allowed the particle removal energy, contact cross-sectional areas, and collapse film energies to be determined, that is, the key parameters in surface rheology. 
Surface pressure $\Pi$ versus surface area $A$ isotherms can be determined for monoparticulate layers by means of Langmuir trough film, in order to obtain information on particle sizes, particle-particle repulsive interactions, and wettabilities. Upon compressing the layers, collapse takes place at a certain pressure $\Pi_{c}$, at which the particles are forced out of the air-water interface. Beyond this point, it may be presumed that the compression work done on the system is entirely channeled into the removal of particles from the interface [14]. The removal energy $E_{r}$ for one particle can be written as follows:

$$
E_{r}=\Pi_{c} A_{c},
$$

where $A_{c}$ is the area per particle at collapse $(=A / N, A$ is the actual film balance area at $\Pi_{c}, N=(\mathrm{m} / \rho) /\left(4 R^{3} \pi / 3\right)$ is the number of all particles spread onto the water surface, $R$ is the particle radius, and $\rho$ is the particle density). Information on the particle wettability can be obtained assuming equality of $E_{r}$ to the work of adhesion $W_{r}$ [15].

The collapse pressure can be related to the air-water contact angle $\theta$, for monodisperse and spherical particles, according to:

$$
\Pi_{c} A_{c}=\gamma_{L V} R^{2} \pi[1 \pm \cos \theta]^{2},
$$

where $\gamma_{L V}$ is the air-water surface tension. If a particle is removed from the interface into the upper phase, then the cosine in the brackets is taken positive, and $\theta$ signifies the receding contact angle $\theta_{R}$; if it moves into the lower phase, the cosine is taken negative (advancing contact angle $\left.\theta_{A}\right)$. A position of a solid spherical particle at the airwater interface, for hydrophilic $\left(\mathrm{CA}<90^{\circ}\right)$ and hydrophobic $\left(\mathrm{CA}>90^{\circ}\right)$ spherical particles is shown in Figure 1.

For the closest packed (hexagonal) arrangement of the monodisperse and spherical particles at collapse (i.e., if the maximum surface coverage SC $=\left(R^{2} \pi / A_{c}\right)=0.91 \mathrm{can}$ be reached during the compression), the contact angle can be calculated from the following expression [14]:

$$
\cos \theta= \pm\left[\left\{\frac{\left(2(3)^{1 / 2} \Pi_{c}\right)}{\left(\gamma_{L V} \pi\right)}\right\}^{1 / 2}-1\right] .
$$

The number of particles per unit area for hexagonal close packing is $N_{p}=1 /\left[2(3)^{1 / 2} R^{2}\right]$ and is dependent only on $R$ and corresponds to the contact cross-sectional area $A_{c c}=$ $1 / N_{p}$. In this case, the contact angle can be determined without knowing the particle size and density. The collapse energy $E_{c}$ can be calculated by integration of the isotherm plot $\Pi(A)$ from $A_{\infty}$ - the area for a particle at which the surface pressure does not exceed the zero value to the collapse area $A_{c}[4]$.

2.3. Dilational Modulus of a Composite Surface-Solid Particles Covering a Variable Area. The difficult task is to derive the measured stress (surface tension change) resulting from an externally applied two-dimensional (dilational) strain (surface area change). The complication for a composite

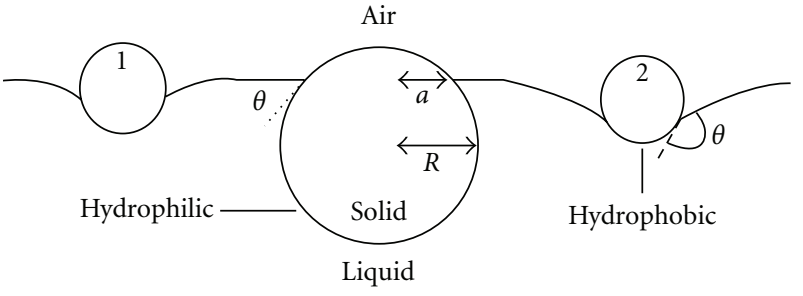

FIGURE 1: Schematic drawing of a spherical particle composed of hydrophilic $\left(\mathrm{CA}<90^{\circ}\right)$ and hydrophobic $\left(\mathrm{CA}>90^{\circ}\right)$ material of radius $R$ showing its position at an air-water interface determined by the contact angle $\theta$ where gravitational effects are negligible, for spheres of $\mu \mathrm{m}$-diameter.

surface is its nonuniformity which leads to an uneven distribution of the applied strain and the resulting effect on the measured stress.

A solid particle which is spherical and so small (in reference to the capillary length, i.e., $R \ll\left(2 \gamma_{L V} / \rho_{L} g\right)^{1 / 2}$, where $\gamma_{L V}$ and $\rho_{L}$ are the surface tension and density of the liquid phase, resp.) that gravity can be ignored if compared to the surface forces will adopt a position in the air-fluid interface which is fully determined by the wetting angle (Figure 1). The area effectively occupied by such particles when there are $n$ of them per unit surface area $A$ is given by

$$
A_{p}=n \pi R^{2} \sin ^{2} \theta .
$$

Considering the total surface covered with a collection of the solid particles and remaining particle-free liquid surface (having $E_{\text {free }}$ modulus), for the modulus of the composite surface $E_{\text {com }}$ we have [3]

$$
E_{\mathrm{com}}=\frac{E_{\text {free }}}{\left\{1+n \pi R^{2}\left[\left(2 E_{\text {free }} \cos ^{2} \theta / \gamma_{L V}\right)-\sin ^{2} \theta\right]\right\}} .
$$

As can be noticed, the presence of partially wetted spherical particles can either increase or decrease the apparent dilational modulus of the whole surface depending on the sign of the term within brackets in the denominator of (8). Thus, when $\theta$ is close to $90^{\circ}$, or when $E_{\text {free }} / \gamma_{L V}$ (values $\sim 0.1$ are found in practice) is very small, there will be increase. In contrast, when $\theta$ is close to $0^{\circ}$ or when $E_{\text {free }} / \gamma_{L V}$ is large, the surface dilational modulus will decrease due to the presence of particles.

\section{Materials and Methods}

3.1. Materials. Distilled water, used for Langmuir trough isotherm studies and contact angle measurements, was taken from a water deionization apparatus (Millipore, conductivity $0.05 \mu \mathrm{Scm}^{-1}$ ) with pH $5.8 \pm 0.1$, and surface tension $\gamma_{L V}=$ $72.5 \pm 0.1 \mathrm{mN} \mathrm{m}^{-1}$. Original seawater was collected at Jelitkowo (Gulf of Gdańsk, Baltic Sea, Poland) on December 7-9, 2006 having $\gamma_{L V}=60.5 \pm 0.1$ and $\mathrm{pH} 8.2 \pm 0.1$. As the model solid material, in Langmuir trough measurements, the following particles of differentiated wettability were chosen: silica microsphere (mean diameter \pm standard deviation; 
$88.00 \pm 10.56 \mu \mathrm{m})$, talc $(22.94 \pm 2.78 \mu \mathrm{m})$, and combustion dust $(3.79 \pm 0.48 \mu \mathrm{m})$.

\subsection{Methods}

3.2.1. Langmuir Trough and Stress-Relaxation Measurements. For the determination of surface pressure versus surface area isotherms, a laboratory built Langmuir trough-Wilhelmy plate system was used, described in detail elsewhere [1].

The surface pressure was measured with a Wilhelmy plate technique using a piece of filter paper (Whatman No. 1, Madstone, England; $5 \mathrm{~cm}$ wide) attached to the arm of a force sensor (GM 2 + UL 5, Scaime, France); they were accurate to within $0.1 \mathrm{mN} \mathrm{m}^{-1}$.

In order to register force-area isotherms, the surface area in the trough was continuously decreased during the compression from 850 to $25 \mathrm{~cm}^{-2}$ at a constant rate of $3 \mathrm{~cm} \mathrm{~s}^{-1}$. It corresponds to the surface deformation velocity $u=\Delta A / \Delta t$ equal to $0.95 \mathrm{~cm}^{2} \mathrm{~s}^{-1}$. Any relaxation process in films leads to the surface viscoelasticity and may affect the shape of isotherms, and consequently the recovered film parameters. As shown in [9], the effect depends on the dimensional parameter Deborah number (De) defined as the ratio of the film relaxation time $\tau$ to the time of observation $t_{\text {obs }}\left(=[(d A / A) / d t]^{-1}\right)$. For several marine film samples already studied in the Baltic Sea [2], the relaxation times were found to lie in rather narrow ranges [2]: $\tau_{1}=(1.3-2.9 \mathrm{~s})$ and $\tau_{2}=(10.1-25.6 \mathrm{~s})$. The film deformation rate adapted in these isotherm studies leads to De number values as low as 0.07, that is, much less than unity, and the interfacial system appears to be in its quasi-equilibrium thermodynamic state.

A new type of Langmuir trough has been used in this study to perform stress-relaxation studies, adapted after [16]. A solid PTFE frame, or barrier, is placed in a rectangular plastic tray of dimensions $90 \mathrm{~cm} \times 60 \mathrm{~cm} \times 6 \mathrm{~cm}$. The barrier has four, rigid solid sides $60 \mathrm{~cm}$ long, and $5 \mathrm{~cm}$ high. The four sides are hinged at the corners so that they provide a continuous, leak-free enclosure. The walls have PTFE pegs underneath so that liquid can flow under the walls to create a well-defined interfacial area inside the barrier. The barrier contains the film of interest, which is omnidirectionally expanded or compressed by flexing the corners, thus changing the shape of the barrier. Two opposite corners of the barrier are connected to a geared stepper motor. The steeper motor system is driven and controlled via a PC-class computer. The drive movement is accurate to $0.1 \mathrm{~mm}$. On driving the corners together or apart the interfacial area inside the barrier is changed stepwise from its initial value $A_{0}=1600 \mathrm{~cm}^{2}$. The surface pressure is measured with a Wilhelmy plate dipping into the interface, situated at the centre of the film, suspended from a force transducer. The surface pressure-time response to a rapid, step $(\Delta t=0.2-1.5 \mathrm{~s})$ relative area deformation $\Delta A / A_{0}(=0.07-0.23)$ is registered to derive the dynamic surface rheology parameters.

Solid samples $(\sim 600 \mathrm{mg})$ were carefully sprinkled onto the trough water surface by using a spatula. A particle dust cloud generator was also used in this study. A vibration feeder supplies the test particles to the fun-generated air

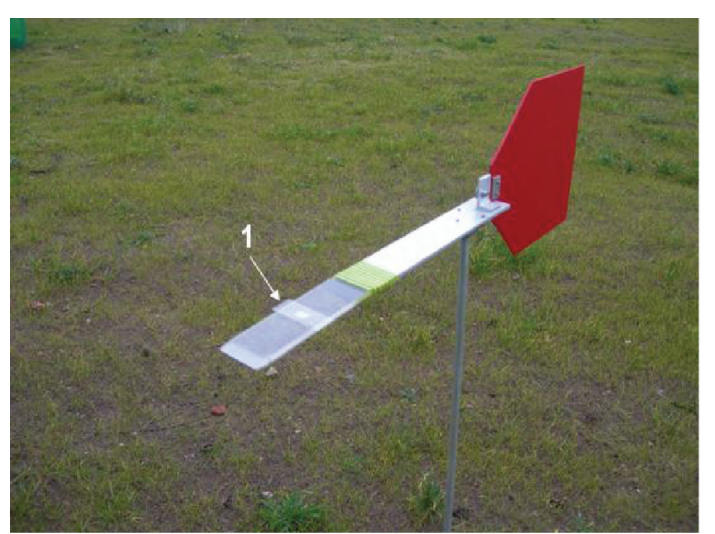

FIGURE 2: Natural dust deposition sampler system with a horizontal deposition plate to collect particles (1), self-oriented to the wind direction by wing (adapted after [6]).

stream. The model particles are mixed with an air stream and blown upward. The air velocity, at the middle of the outlet stack oriented over the water surface, was 3-4 $\mathrm{m} \mathrm{s}^{-1}$. The particle surface density (number $\mathrm{cm}^{-2}$ ) and particle diameter distribution were derived from the microscope picture analyses of the greased cover glass palates. The dry deposition collector was placed nearby the studied surface. Detailed information on the applied optical method and the sampling procedure can be found elsewhere [6].

3.2.2. Natural Dust Solid Particles Collection. Figure 2 shows a top of the dry deposition sampler, and the deposition plate is used in this study to collect the airborne particles. The sampler was designed to provide minimum airflow disruption. A pivoting support system pointed the horizontally oriented deposition plate into the wind. The deposition film consisted of a greased (with Apiezon grease type $L$ as a deposition sampling substrate not absorbing water vapor) cover glass supported on a microscope slide glass $(24 \times 40 \mathrm{~mm})$ placed in a groove on the deposition plate. More details on dry deposition methodology with the mentioned sampler can be found in [6].

(1) Particle Water Contact Angle Characterization. Since the model materials are in a powdered form, there is no universal method for solid surface/surfactant-containing water contact angle determination. Here we used three most widely used methods to select the most practical one giving the most accurate and reproducible CA values.

(2) Sessile Drop Technique. This technique is among the most popular methods used in surface chemistry laboratories, especially due to their simplicity. In the sessile drop technique a small liquid drop (2-5 $\mathrm{mm}$ diameter) was placed on the solid surface (microscope glass slide covered with a thin layer of the studied solid material) using a microliter syringe. Horizontal sessile drop profiles, taken with a digital camera, were analyzed with the Axisymmetric Drop Shape AnalysisProfile (ADSA-P) technique, from which all the sessile drop 


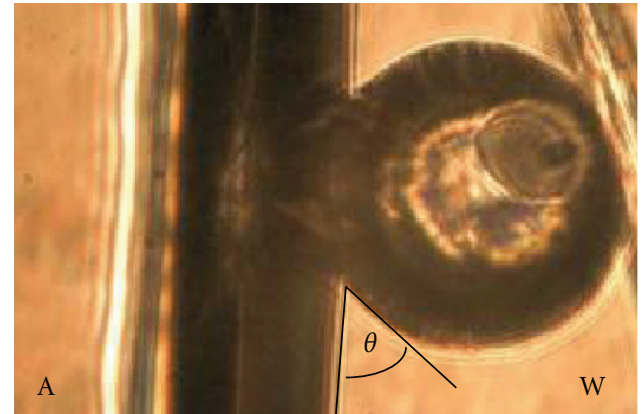

(a)

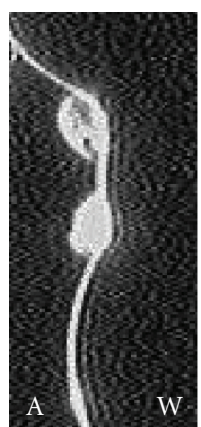

(b)

FIGURE 3: Exemplary photographic records of model silica microsphere (a) and talc particle (b) floating at the air (A) —original seawater (W) interface taken for evaluation of CA in direct microscopic method.

parameters such as $\mathrm{CA}$, contact radius, and volume can be extracted. The adapted apparatus is described in [17].

(3) Microscope Technique. The surface of solid particles was characterized by measuring the static contact angles from the microscopic images of the particles placed at the air-water interface formed between two plane-parallel microscope glass slides. The details of the applied optical method can be found elsewhere [4]. An example of photographic records of the model dust material contained in seawater is presented in Figures 3(a) and 3(b).

(4) Thin Layer Wicking Technique. The most reliable technique for the measurement of the contact angle on the powered samples is "the thin layer wicking technique" based on the Washburn equation $[18,19]$. In this method, a powdered sample is deposited on a microscopic glass slide in the form of aqueous slurry on which a thin layer of the powdered mineral has been formed. An aqueous suspension of the model material was prepared by dispersing a known amount of sample material in distilled water (5\% weight by volume). The appropriate volume of the suspension was withdrawn with a pipette and sprayed over a glass slide $(24 \times 60 \mathrm{~mm})$. After drying the sample at $110^{\circ} \mathrm{C}$, one end of the glass slide was contacted with a vial containing cotton wool filled with a spreading liquid (seawater, distilled water, and pentadecane) with the marked appropriate scale $(1-15 \mathrm{~cm})$, as shown in Figure 4 . The liquid will start to move along the horizontallyoriented slide through the capillaries formed between the particles deposited on the glass surface. The velocity of moving liquid line is measured and then converted to the contact angle using the Washburn equation. The calibration procedure, as required, was performed with pentadecane $\left(\mathrm{C}_{15} \mathrm{H}_{32}\right)$ as a reference liquid (giving the complete spreading condition i.e., $\mathrm{CA}=0$ ). It should be borne in mind that such a method gives the so-called advancing CA that is usually higher than the equilibrium Young CA. The applied apparatus and methodology is described in details in [7].

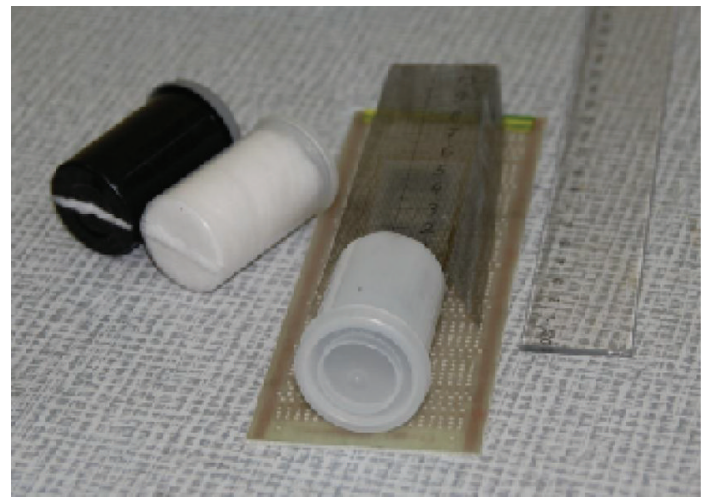

Figure 4: Cylindrical cotton wool filled plastic containers saturated with probe liquids attached to a horizontal glass slide covered with a powdered material used in "the thin layer wicking technique" to determine CA of the model materials (adapted after [7]).

\section{Results and Discussion}

4.1. Monoparticulate Solid Layer Interfacial Parameters. The surface pressure $(\Pi)$ versus film area $(A)$ measurements of composite layers provided fruitful information about the particle size distribution, particle-particle and particle subphase interactions, and surface wettability signatures [20]. The surface energetics of the composite surface can be quantified by means of the surface parameters evaluated according to (4)-(6). Typical surface pressure $(\Pi)$ versus surface area $(A)$ isotherms obtained for the model hydrophobic particles are depicted in Figures 5(a)-5(c). Compression led to a collapse phenomenon of the structured monoparticle layers. The extrapolation procedure for determination of $\Pi_{c}$ and $A_{c}$ for silica monoparticles is shown in Figure 6. The collapse of solid monoparticulate layers is not a real collapse phenomenon (e.g., surface pressure does not drop to zero at this point). The "knee" in the curve, taking place in a surface pressure range about $15 \mathrm{mN} \mathrm{m}^{-1}$ for microsphere, is followed to area in which the particles become close packed. Above the particular surface pressure, different for the model materials, depending on their hydrophobicity, 


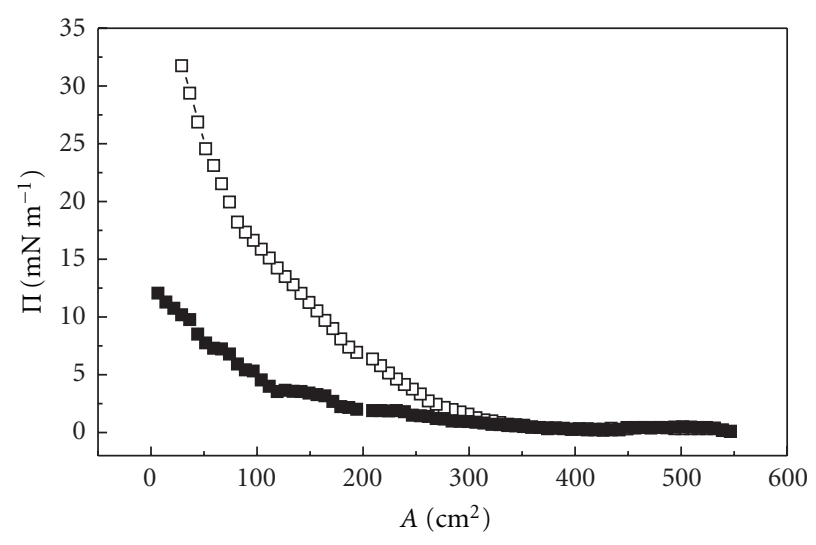

(a)

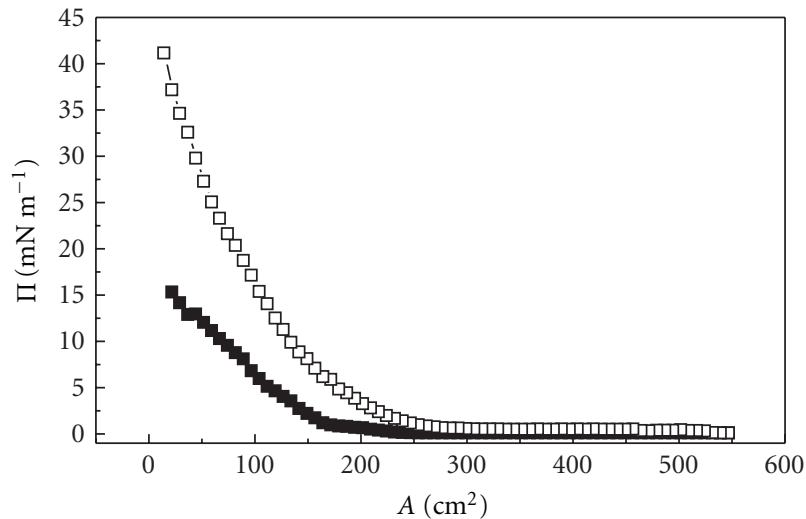

(b)

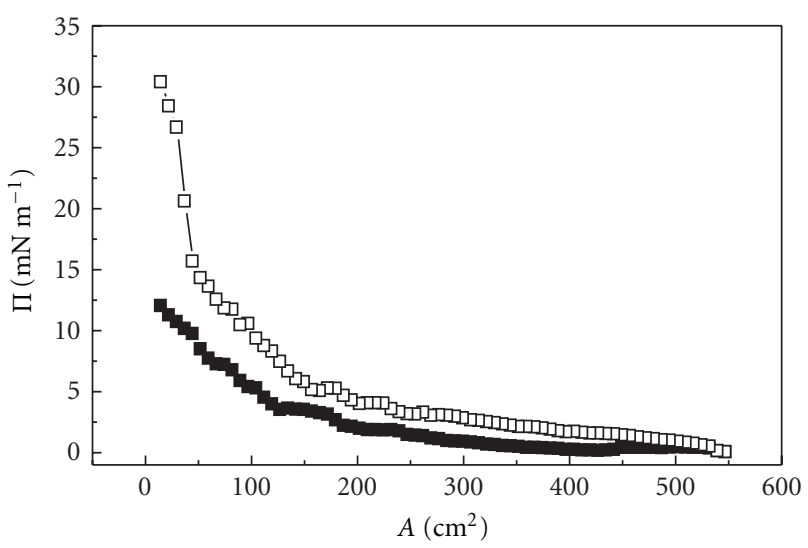

(c)

Figure 5: Surface pressure ( $\Pi$ ) versus surface area (A) curves for (a) silica microsphere $\square$, (b) talc $\square$, and (c) combustion dust $\square$ particles spread on an original seawater subphase collected at Jelitkowo (on 08.12.2006). Reference particle-free isotherm $\boldsymbol{\square}$. Water sample at $T=$ $22.4^{\circ} \mathrm{C}$ and $\mathrm{pH}=8.4$.

monolayer pleated that leads to gradually create a threedimensional monoparticulate layer. The monolayer collapse effect is dependent on the size and nature of the particles. Consequently, continued compression above this point causes a slow further increase in surface pressure, and the particles are gradually squeezed out of the interface. The steepness of the surface pressure-surface area isotherms facilitated the determination of the packing area, which, by analogy to monolayers formed by surfactants-is referred to as the contact cross-sectional areas CCSA. CCSA can be determined from the $\Pi-A$ isotherms by fitting a straight line to the steepest, nearly linear (solid state) part of the isotherm (the limiting area for insoluble films is determined in the same way). CCSA and collapse energies $E_{c}$ ( $E_{c}$ results from the integration of the isotherm plot between $\Pi=0$ and $\Pi=\Pi_{c}$ ) provided semiquantitative information on the strength of structural interfacial forces. That is, the higher the particle hydrophobicity, the greater the structural strength of the monoparticulate layer. So, the value of CCSA refers to the particle hydrophobicity; greater values of CCSA stand for higher hydrophobicity of particles [20]. Monoparticulate layers which were formed from the most hydrophobic spheres had a structural strength greater than that of those which were formed from the least hydrophobic material as revealed by $E_{c}$ and CCSA values collected in Table 1 . The collapse energy $E_{c}$, necessary to compress the most hydrophobic particles (combustion dust) into a closepacked hexagonal array, was almost two times greater than that required for the compression of the least hydrophobic particles (talc and microsphere). The total pair-interaction energy for interfacial particles floating at liquid-gas interface is expressed as $V_{T}=V_{A}+V_{R}+V_{S}+V_{D}$ (where $V_{A}$ is the van der Waals attraction; $V_{R}$ is the electric-double-layer repulsion; $V_{S}$ is the structural interaction energy; $V_{D}$ can be either attractive (hydrophobic attraction energy) or repulsive (salvation repulsion energy) depending on the hydrophobichydrophilic nature of the particle surface. If the water contact angle is lower than $15^{\circ}$, the surface will be hydrophilic, and above $64^{\circ}$ it should be considered as hydrophobic [20].

The Langmuir trough method makes possible to study the wettability of mineral particles (with CA) by a surfactant solution. It is also accepted that the surface pressure measurements can be related to the work necessary for the compression of particulate layers, and for the particle removal $W_{r}$ from the liquid-gas interface. One could obtain the contact angles in sea surface containing solid particles if $E_{r}$ and $W_{r}$ 


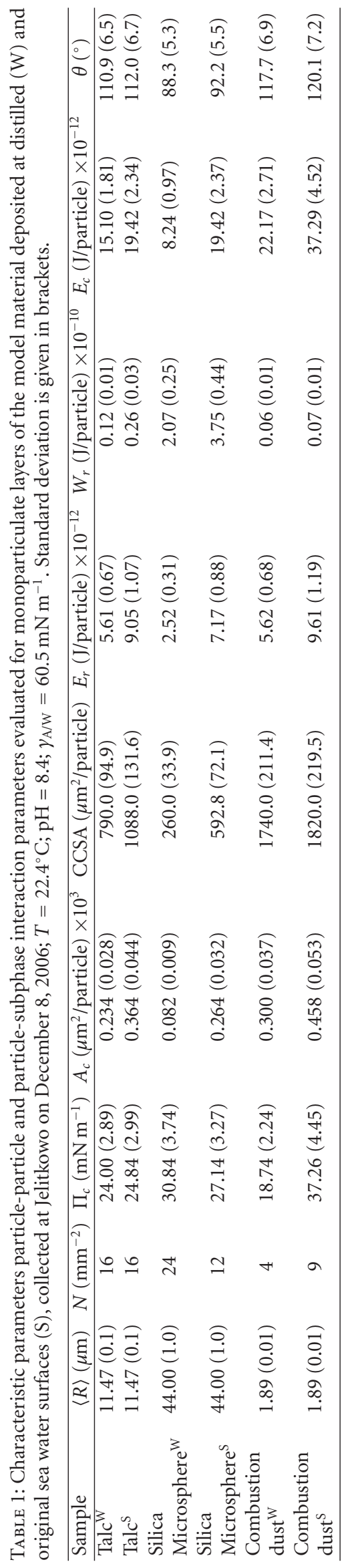


TABLE 2: Contact angles (CA) of studied mineral dust particles with distilled (W) and original sea water (S) derived by means of different techniques. $r^{*}$ : pore radius.

\begin{tabular}{lcccc}
\hline & \multicolumn{2}{c}{ CA determination technique } \\
Sample/phase & Sessile drop & Isotherm derived from $(8)$ & Microscope technique & Thin layer wicking technique \\
\hline Talc $^{\mathrm{W}}$ & $108.6 \pm 6.8$ & $110.9 \pm 6.5$ & $88.8 \pm 5.4$ & $80.3 \pm 4.8$ \\
Talc $^{\mathrm{S}}$ & & $112.0 \pm 6.7$ & $93.9 \pm 5.7$ & $\left(r^{*}=402.6 \mathrm{~nm}\right)$ \\
\hline Microsphere $^{\mathrm{W}}$ & $99.4 \pm 6.1$ & $88.3 \pm 5.3$ & $62.0 \pm 4.2$ & $86.7 \pm 5.2$ \\
Microsphere $^{\mathrm{S}}$ & & $92.2 \pm 5.5$ & $68.1 \pm 4.8$ & $\left(r^{*}=1301.1 \mathrm{~nm}\right)$ \\
\hline Combustion dust $^{\mathrm{W}}$ & $120.6 \pm 7.1$ & $117.7 \pm 6.9$ & $116.9 \pm 6.0$ & $83.0 \pm 4.9$ \\
Combustion dust $^{\mathrm{S}}$ & & $120.1 \pm 7.2$ & $126.2 \pm 6.8$ & $124.2 \pm 8.3$ \\
\hline
\end{tabular}

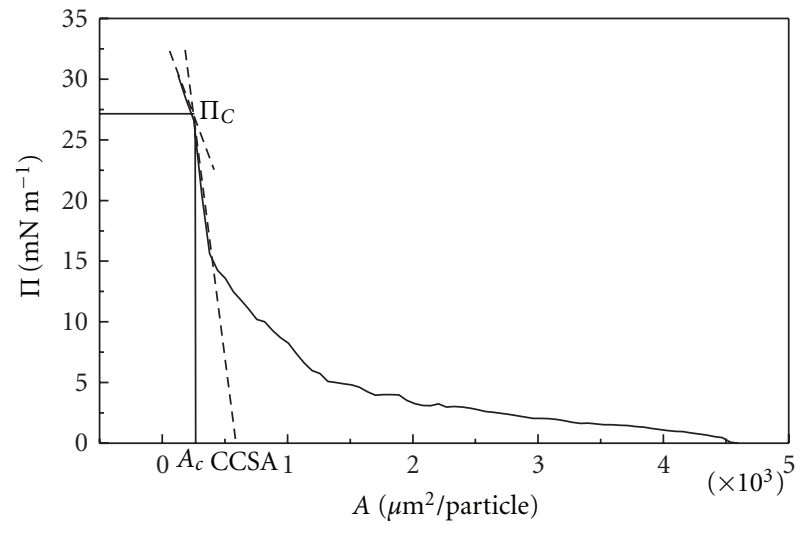

FIGURE 6: Surface pressure (П) versus surface area $(A)$ isotherm, for silica microsphere layers deposited at original seawater collected at Jelitkowo $\left(08.12 .06 ; \mathrm{T}=22.4^{\circ} \mathrm{C} ; \mathrm{pH}=8.4\right)$ as an exemplary plot illustrating determination and extrapolation procedures to derive collapse pressure $\Pi_{c}$, surface area $A_{c}$ at the collapse pressure, and contact cross-sectional area (CCSA).

are equal. Three different CA wettability measurement techniques were taken in for the determination of contact angle of the model powders. The particle-subphase interaction can be responsible for the observed difference between contact angles derived from the isotherms (larger by $8-10^{\circ}$ ) than these obtained from the direct contact angle measurements (the sessile drop, microscope, and thin layer wicking technique), as can be noticed from Table 2. The higher values (by $5-6^{\circ}$ ) of the contact angle were observed for the model particles in contact with the surfactant-containing seawater if referred to the distilled water. The effect is attributed to the autophobing phenomenon leading to the solid surface free energy decrease in the surfactant water solutions accompanied by the corresponding increase of $\theta$ [21].

To sum up, the effect of surfactant-containing seawater on the structural strength and particle-particle interaction was expressed in higher hydrophobicity of the model materials deposited at the seawater surface $\left(A_{c} \uparrow\right.$ and CCSA $\left.\uparrow\right)$, higher twice $E_{c}$, larger is the energy required to remove the particle $\left(E_{r} \uparrow\right)$, and corresponds well with an increase of the contact angle $(\theta \uparrow)$. The largest parameters values were noticed here, for the most hydrophobic solid material, that is, combustion dust particles. These observations are related to differences in the structural force strength between the model composite particle layers. Moreover, there may be a strong fluctuation of the liquid-air interface due to the trapping the test particles, which probably results in a lower value of the wetting angle (the capillary forces supply significant kinetic energy for the particles during their trapping) which, due to the elasticity of water-air interface, leads to an oscillation of the particles [4]. It was also found that the collapse pressure and contact angles of hydrophobic particles can be depended on the amount of spread particles to a certain extent [15]. The effect was attributed to a surface pressure gradient along the very cohesive particulate layer.

4.2. Composite Surface Elasticity. The composite modulus $E_{\text {com }}$ of the particle-incorporated seawater interface can be theoretically obtained from (8) with the following entering input data characteristics for the model materials: particle concentration, diameter distribution, and solid/water phase contact angles. $E_{\text {com }}$ values were comparable to the result obtained from the isotherm studies, and the ones estimated for the clean sea surface (without particles), as collected in Table 3. Theoretically predicted values of $E_{\text {com }}$ were in agreement with the experimental data within a range of $3 \%$ error, for microsphere and combustion dust, although apparently higher. A variety was considerably highest for talc particles $(\approx 21 \%)$, that has the unique surface properties. Particles of talc have the shape of platelets due to the layer structure of the mineral. It is well known that the basal surfaces are hydrophobic, while the edge surfaces are hydrophilic [22]. The hydrophobicity of the basal surfaces arises from the fact that the atoms exposed on the surface are linked together by siloxane ( $\mathrm{Si}-\mathrm{O}-\mathrm{Si}$ ) bonds and do not form strong hydrogen bonds with water. The edge surfaces are composed of hydroxyl ions, magnesium, silicon, and substituted cations, all of which undergo hydrolysis. As a result, the edges are hydrophilic and can form strong hydrogen bonds with water molecules and polar substances. The presence of the particles in sea surface film caused an increase of the apparent modulus by a factor $K\left(E_{\text {com }} / E_{\text {free }}=\right.$ 1.29-1.58), as summarized in Table 3. 


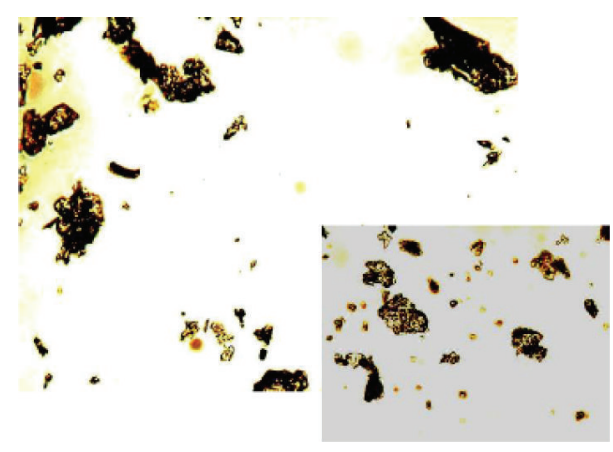

(a)

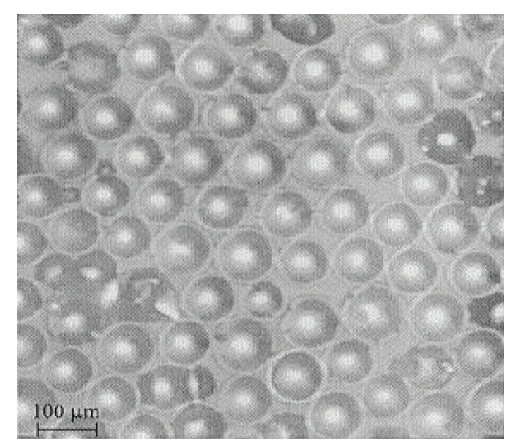

(b)

Figure 7: (a) Atmospheric irregularly shaped dust particles on the deposition film photographed in Baltic Sea coastal areas (at Gdynia, mean diameter $=5.86 \pm 0.85 \mu \mathrm{m}$ ). (b) Monoparticular layer of silica spheres at A/W interface.

TABLE 3: Elasticity modules of composite surfaces obtained from experimental isotherm measurements (a), and theoretical predictions (from (8)) (b). Original sea water collected at Jelitkowo on 08.12.06; $\mathrm{T}=22.4^{\circ} \mathrm{C}, \mathrm{pH}=8.4, \gamma_{\mathrm{A} / \mathrm{W}}=60.5 \mathrm{mN} \mathrm{m}^{-1}$. $K$ is the ratio $E_{\text {isoth }} / E_{\text {free }}$, where $E_{\text {free }}$ is the modulus for clean particle-free seawater surface (c). Standard deviation is given in brackets.

\begin{tabular}{|c|c|c|c|}
\hline Sample & $E_{\text {isoth }}{ }^{\mathrm{a}}\left(\mathrm{mN} \mathrm{m}^{-1}\right)$ & $E_{\text {com }}{ }^{\mathrm{b}}(\mathrm{mN} / \mathrm{m})$ & $K$ \\
\hline \multicolumn{4}{|l|}{ Talc } \\
\hline \multicolumn{4}{|l|}{$\bar{R}=11.47 \mu \mathrm{m}$} \\
\hline$N=16 \mathrm{~mm}^{-2}$ & $10.60(1.26)$ & $12.90(1.55)$ & 1.29 \\
\hline \multicolumn{4}{|l|}{$\theta=112.0^{\circ}$} \\
\hline \multicolumn{4}{|l|}{ Microsphere } \\
\hline \multicolumn{4}{|l|}{$\bar{R}=44.00 \mu \mathrm{m}$} \\
\hline$N=12 \mathrm{~mm}^{-2}$ & $12.96(1.57)$ & $13.39(1.61)$ & 1.58 \\
\hline \multicolumn{4}{|l|}{$\theta=92.2^{\circ}$} \\
\hline \multicolumn{4}{|l|}{ Combustion dust } \\
\hline \multicolumn{4}{|l|}{$\bar{R}=1.89 \mu \mathrm{m}$} \\
\hline$N=9 \mathrm{~mm}^{-2}$ & $11.84(1.43)$ & $12.25(1.48)$ & 1.45 \\
\hline \multicolumn{4}{|l|}{$\theta=120.1^{\circ}$} \\
\hline Jelitkowo & $8.17^{c}(1.03)$ & - & - \\
\hline
\end{tabular}

4.3. Morphology, Chemical Composition, Spatial Distribution, and Wettability of Natural Dry Deposition Events at Baltic Sea Coastal Areas. In order to validate the dilational composite modulus approach in reference to the natural particular dust deposition event conditions, that is, the seawater interface incorporated with natural mineral dust particles, dry dust characterization studies were performed in Baltic Sea shore regions (Gulf of Gdańsk, Poland) in September 2006. Mineral fly dust mainly consists (identified by X-ray diffraction) of a mixture of silicates (clay minerals, feldspars, quartz) and sometimes carbonates and sulfates [23]. It was observed that the mineralogical composition of the dust directly depends on its origin [23]. By order of abundance, the minerals identified in the dust were as follows: illite $>$ quartz $>$ smectite $>$ palygorskite $>$ kaolinite $>$ calcite $>$ dolomite $>$ feldspars [24]. The mean density of the compounds was $2.65 \mathrm{~g} \mathrm{~cm}^{-3}$ [25]. Morphologically, mineral atmospheric particles have an irregular shape (Figure 7), which demands applying, in the aim of the particle diameter distribution to be characterized, the equivalent maximum diameter defined as the maximum diameter corresponding to an axisymmetric drop with the same volume as the actual drop $\left(\sqrt{\left\langle d_{\max }^{2}\right\rangle} \equiv 2 \sqrt{A / \pi^{\prime}}\right.$; the drop mean quadratic diameter- $\sqrt{\left\langle d_{\max }^{2}\right\rangle}$; particle area-A). For comparison, a monoparticular layer of the silica microspheres at the airwater interface is shown in Figure 7(b). Histograms of the dust particle diameter distribution, for a 24-hour collection time, registered at Brzezno (a), Sopot (b), and Gdynia (c) are depicted in Figure 8. Mean values of the diameter were ranging from 5.8 to $7.6 \mu \mathrm{m}$ depending apparently on the distance from the shore line. As evidenced from the dust diameter profile taken along the Sopot pier shown in Figure 9(a), the mean value steeply dropped down from $5.5 \mu \mathrm{m}$ to around $3.5 \mu \mathrm{m}$ within the first 70 meters from the shore line remaining almost the same later on. The particle number flux (mean value) at the shore line was equal to 47.5 per $1 \mathrm{~mm}^{-2}$ and continuously decreased with the distance passed toward the sea attaining 26.3 at the pier end (see Figure 9(b)). A deposit gauges are usually operated on a monthly basis with results being expressed as the mean daily deposition rate $\left(\mathrm{mg} \mathrm{m}^{-2}\right.$ day $\left.^{-1}\right)$ of undissolved solids. The ambient daily dry deposition rate spatial characteristics collected in the Sopot pier revealed an exponential decay character with the values ranging from 10.82 to $2.30 \mathrm{mg} \mathrm{m}^{-2} \mathrm{day}^{-1}$ (Figure 9(c)). For example, dust gauges located within $100 \mathrm{~m}$ off heavily trafficked roads evidenced the deposition rates frequently exceeded $200 \mathrm{mg} \mathrm{m}^{-2} \mathrm{~d}^{-1}$. The following approximate dust fluxes could be expected in the open country-village area (general deposits) $\sim 50 \mathrm{mg} \mathrm{m}^{-2} \mathrm{~d}^{-1}$, commercial centre of town $\sim 100 \mathrm{mg} \mathrm{m}^{-2} \mathrm{~d}^{-1}$, and purely industrial area $\sim 150 \mathrm{mg} \mathrm{m}^{-2} \mathrm{~d}^{-1}$ [26].

Large quantities of the suspended solid particles of different size spectra are often found in estuaries, shallow water, and near ocean sewage outfalls of large cities [27]. A numerous part of suspended particulate matter in estuaries and coastal waters can exist as aggregates, or flocs, which are composed of inorganic material particles and biogenic debris as well as organic matter as cells, cellular exudates, 


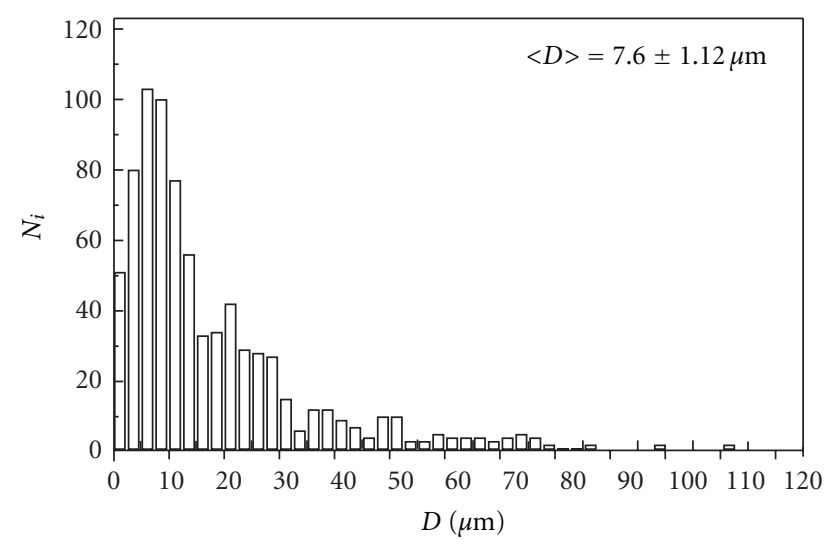

(a)

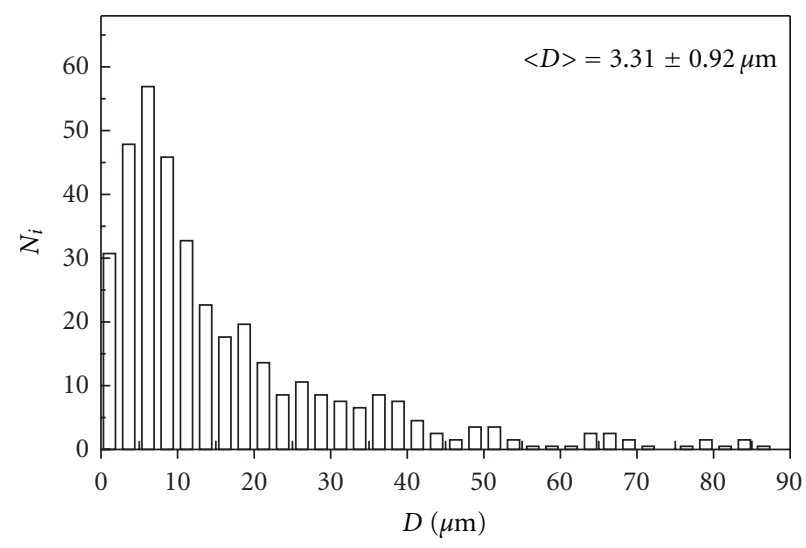

(b)

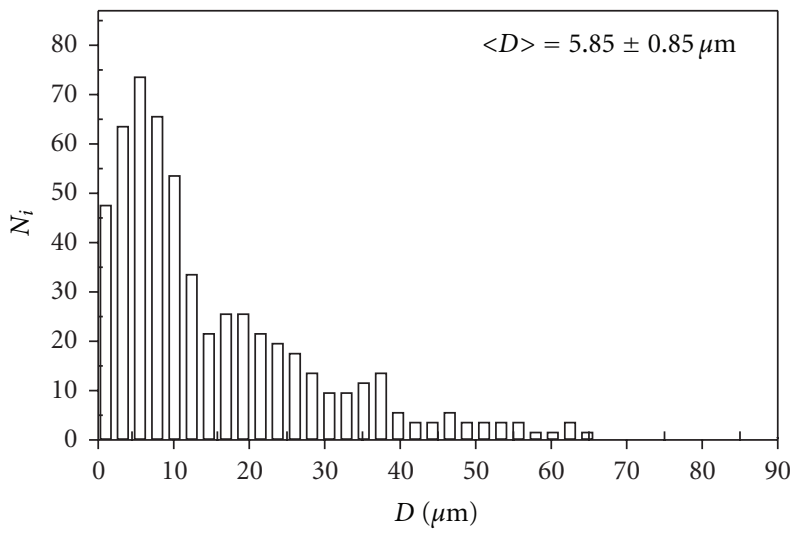

(c)

FIGURE 8: Histogram of the natural dust particle diameter distribution, for a 24-hour collection time, measured at (a) Brzezno (collection point 55-meter distant from the shore line), (b) Sopot (25-meter distant), and (c) Gdynia (5-meter distant).

and humic material [28]. Both the concentration and particle size distribution are primary information for the analysis of the suspended material, and their influence on the change of sea surface film elasticity. Temporal and spatial variabilities in the concentration and composition of the particle material depend on biological, chemical, geological, and physical factors [29]. For instance, the size distribution of suspended particles observed in the Humber Estuary exhibited a large range with the median diameters extending from $50 \mu \mathrm{m}$ in surface water to $500 \mu \mathrm{m}$ near the bed [30]. Whereas, in coastal waters near a sewage outfall in Sydney (Australia), it can be seen that 90 per cent of particles lie between diameters 0.4 and $2.4 \mu \mathrm{m}$. The mass-particle size distributions of mineral dust particles transported long distances are continuously reshaped by the dry removal of particles, and under some circumstances by mixing or aggregation [31]. The mass median diameters for the north Atlantic were $\sim 2-3 \mu \mathrm{m}$ (2.4 (Bermuda spring); 2.0 (Bermuda summer); 2.3 (Barbados); 1.2 (Izana); 3.0 (at-sea shipcollected). It has also been shown that the typical diameter range of the road (the highway) dust is about 5-30 $\mu \mathrm{m}$ [25].

If it occurs in the marine boundary layer over the remote ocean, the implications for the air-sea exchange of dust will be far different than if the aggregation takes place close to the source region $[32,33]$. CA of the natural dust particles performed by means of direct microscopic and thin layer wicking techniques were varying in a rather wide range from $47.3^{\circ}$ to $106^{\circ}$ depending on the collection site, and probably on a variable proportion of hydrophobic and hydrophilic material composing the particle. In reference to the obtained results, mineral dust consists of variety hydrophobicity properties particles. The sea surface is supposed to be covered by the most hydrophobic particles $\left(\theta>90^{\circ}\right)$, whereas the hydrophilic ones $\left(\theta<90^{\circ}\right)$ are submerged in the subphase layer. Both kinds of materials appear as the mixed, aggregated interfacial structures which possess significant dilational viscoelasticity. The real dust characteristics registered in the shore line of Gdańsk Gulf differed significantly from the model material properties (i.e., irregular particles of smaller diameters with higher surface concentrations), that should lead to the particular elastic properties of natural composed sea surface films.

4.4. Viscoelasticity of Solid Particles Incorporated Seawater Surface. Relaxation processes in the surface films lead to surface viscoelasticity and may affect the shape of isotherms, and consequently the recovered film parameters. The surface pressure-time responses of a natural marine surface film to a rapid $(\Delta t=0.3 \mathrm{~s})$ step relative surface area deformation $\Delta A / A(=0.16)$, for a sample collected at Jelitkowo on 


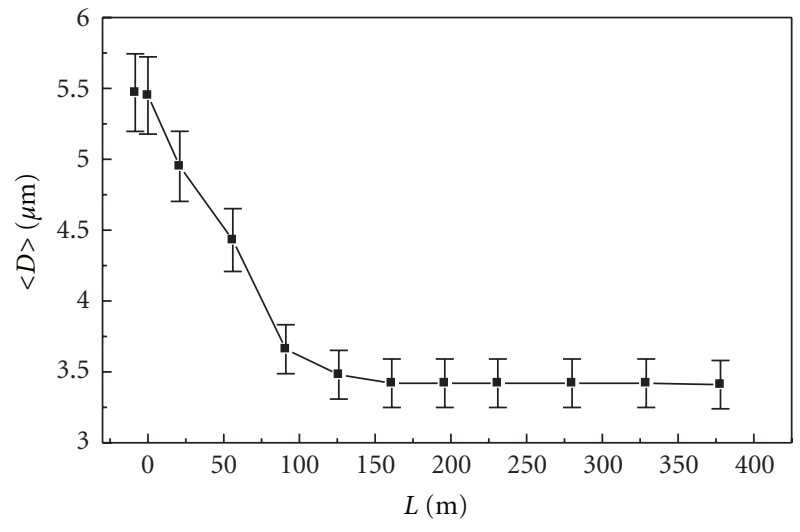

(a)

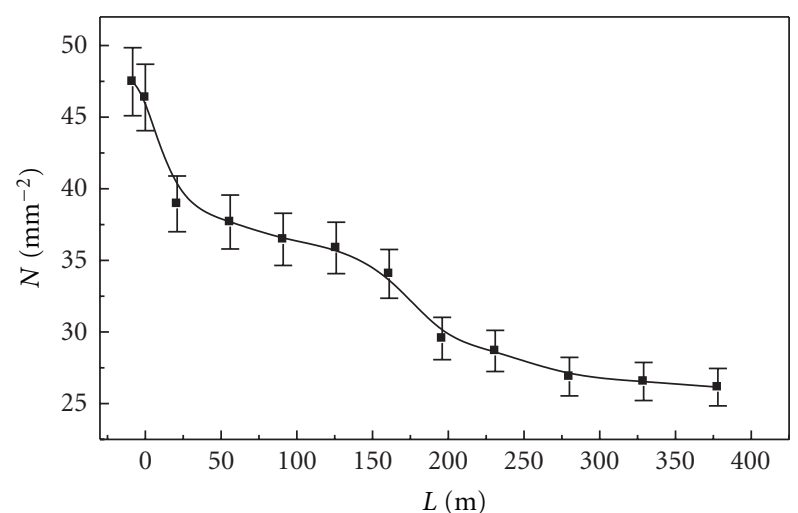

(b)

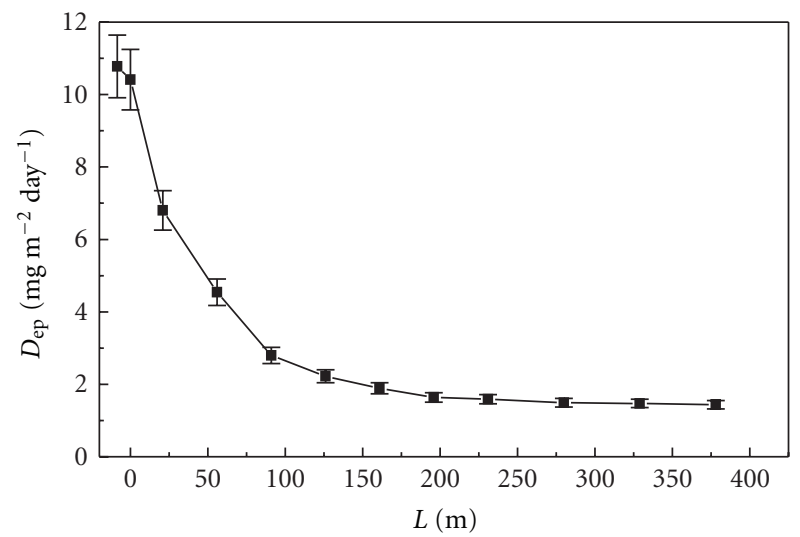

(c)

Figure 9: Mean natural dust diameter spatial (a), particle number flux (b), and mean daily deposition rate (c) profiles, registered along the Sopot pier on september 26, 2006, for a 24-hour period. $V_{10}=4.0 \pm 1 \mathrm{~m} \mathrm{~s}^{-1} ; T_{\text {air }}=21.5^{\circ} \mathrm{C}$.

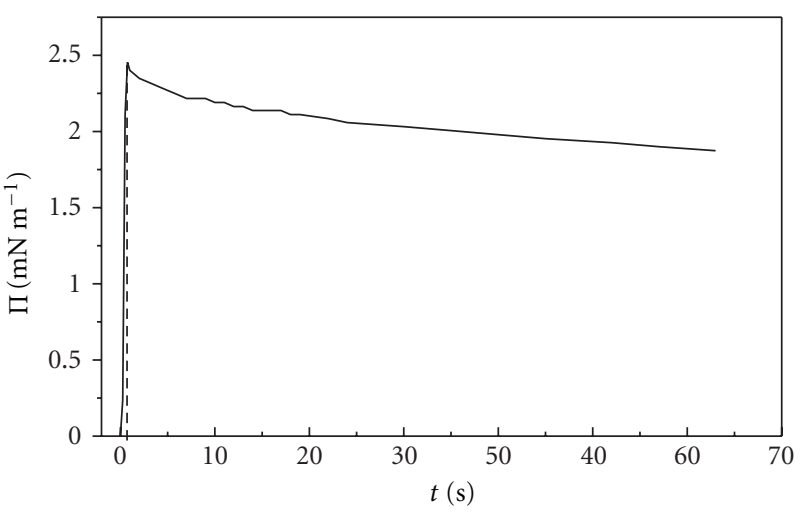

(a)

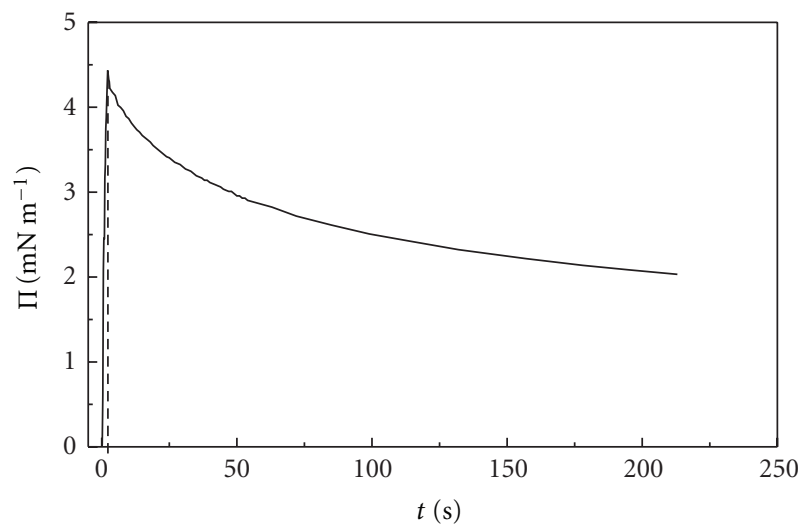

(b)

FIGURE 10: Results of stress-relaxation experiments: $\Pi(t)$ decay dependence of surface pressure versus time after a step rapid $(\Delta t=0.3 \mathrm{~s})$ relative film area $\Delta A / A(=0.16)$ compression, for a marine film sample collected at Jelitkowo on $11.12 .2006\left(\right.$ sample state: $T=19^{\circ} \mathrm{C}$, $\mathrm{pH}$ $=8.2$ ) as a reference particle-free surface (a), and for composite surface (b), that is, monoparticulate talc layer covered the same seawater interface $(\triangle A / A=0.17 ; \Delta t=1.2 \mathrm{~s})$. 


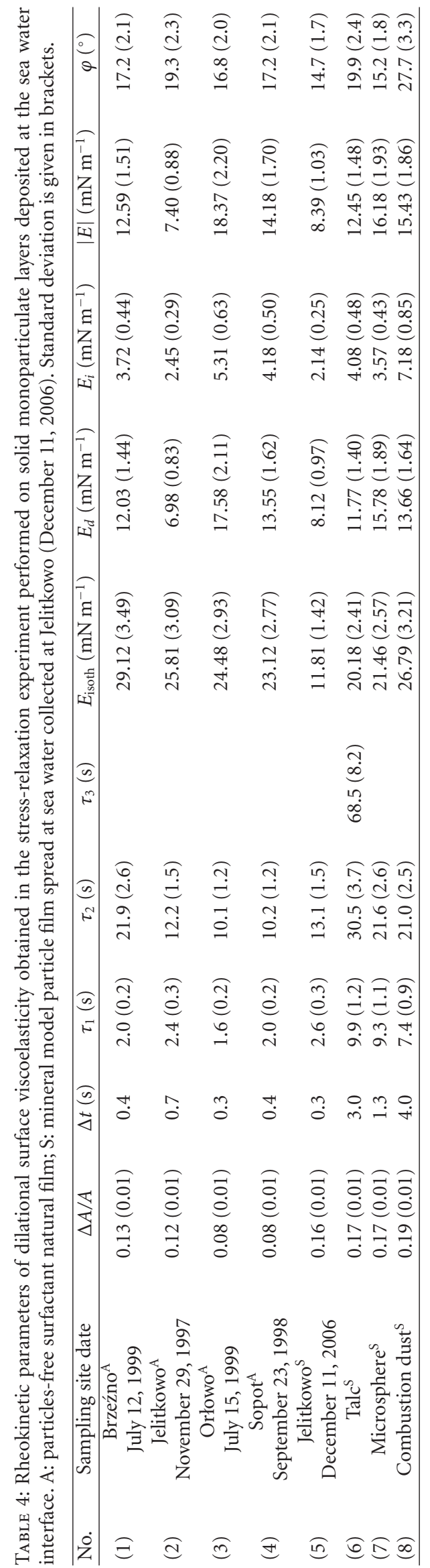


December 11, 2006, and for the same sample of seawater with the floating talc monoparticulate layer $(\Delta t=1.2 \mathrm{~s})$; $\Delta A / A(=0.17)$, are presented in Figures $10(\mathrm{a})$ and $10(\mathrm{~b})$. The rate of the relaxation processes can be analyzed with the firstorder equation (2). The equation applied to the $\Pi$ - $t$ plot from Figure 10 yielded two linear regions. The composite seawater film studies revealed a two- (three-) step relaxation process with the characteristic times $\tau_{1}=(2.6-9.9) \mathrm{s}, \tau_{2}=(13.1-$ 30.5 ) $\mathrm{s}$, and $\tau_{3}=68.5 \mathrm{~s}$ (for the talc-covered surface). So far, for natural surfactant seawater films, relaxation times were found to be in rather narrow ranges $\tau_{1}=(1.3-2.9) \mathrm{s}$ and $\tau_{2}=(10.1-25.6) \mathrm{s}[2]$. The obtained relaxation times for the composite surface films were systematically longer, as a consequence of more complicated (complex) film structure leading to lengthening the time scale of film conformation changes at the interfacial system under surface stress.

The characteristic relaxation times $\tau$, together with the applied step deformation time $\Delta t$, the relative area change $\Delta A / A$, and the remaining surface viscoelasticity parameters (real and imaginary parts of the dilational modulus $E$ ), its loss angle $\varphi$ (from (2)-(3)), and the static isothermal modulus $E_{\text {isoth }}(1)$ are collected in Table 4 . The obtained rheokinetic parameters demonstrated that we are concerned with the complex structurally films having a relatively significant imaginary part of the complex $E(E i /|E| \approx 0.22-$ $0.46)$ with values of the loss angle $\varphi\left(15.2-27.7^{\circ}\right)$ taking particularly high values for the most hydrophobic particlescombustion dust. In contrast, sea surface natural films (supposed to be solid particle free) demonstrated the purely elastic behavior $\left(E_{d} \sim|E| ; E_{d} \gg E_{i}\right)$ with the loss angles $\varphi$ ranging from 14.7 to $19.3^{\circ}$, and $E_{i} /|E| \approx 0.25-0.33$. At compression rates $([\Delta A / A] / \Delta t)$ applied in these studies, the dilational viscoelasticity modulus can not be approximated by $E_{\text {isoth }}$ (comparable values of $E_{\text {isoth }}$ and $|E|$ ). It should be pointed out that a dilational modulus determined by quasiisotherm measurements must be higher than a modulus obtained under nonequilibrium conditions, and the latter values are different from those determined by stepwise compression. In general, for structurally complex natural sea surface films, the surface rheology parameters may significantly differ from each other if derived from static and dynamic studies. Viscoelasticity of the particle-incorporated surfaces revealed time scales of the relaxation processes corresponding to the deformation frequency range 0.9$5.3 \mathrm{~Hz}$ relevant to water wave damping in the capillary-short gravity frequency region [34]. It should be noted that the wind waves Marangoni damping effect can not be explained quantitatively only by the dilational moduli obtained in this work; other aerodynamic parameters of the air/film-covered seawater interactions remain to be taken into account [35].

\section{Conclusion}

Surface pressure $(\Pi)$ versus surface area $(A)$ isotherms determined for monoparticulate solid layers at the airwater interface allowed the effect of hydrophobicity on the particle-particle and particle-subphase interactions to be quantified in terms of the removal energy $E_{r}$, contact cross-sectional areas CCSA, and collapse energies $E_{c}$. Dust material wettability in contact with the seawater affected by the surfactant surface adsorption, resulting from the autophobing phenomenon leading to CA $\uparrow$, was evaluated by contact angle techniques (wicking layer and microscope) applicable to solids appearing in a powdered form. The collected data revealed different wettability of the mineral material with water $\mathrm{CA} \approx 47.3^{\circ}$ to $106^{\circ}$, irregularly shaped particles with the mean diameters $5.8-7.6 \mu \mathrm{m}$, with density of $2.65 \mathrm{~g} \mathrm{~cm}^{-3}$ appearing at the mean daily deposition rates $\left(2.30-10.82 \mathrm{mg} \mathrm{m}^{-2}\right.$ day $\left.^{-1}\right)$ typical for clean marine coastal regions. Surface dilational modulus of composite surfaces $E_{\text {com }}$ obtained using a theoretical approach, in which the solid particle deposition features (surface particle concentration, mean diameter, and solid/water phase contact angles) originated from the dry dust deposition flux laboratory and field studies agreed well with the direct isotherm and stress-relaxation particle-incorporated surface film Langmuir trough measurements. The presence of the hydrophobic particles in sea surface film caused an increase of the apparent modulus by a factor $K=$ $\left(E_{\mathrm{com}} / E_{\text {free }}=1.29-1.58\right)$. The monoparticulate solid particle layers at the seawater-air, studied in the stress-relaxation experiments, revealed a three-step relaxation phenomenon, and demonstrated a viscoelastic surface behavior. In contrast, natural marine surface films (supposed to be particle-free) were found to be purely elastic $\left(E_{d} \gg E_{i} ; \varphi=14.7-19.3^{\circ}\right)$.

So far, an underestimated role played by solid dust incorporated in interfacial region of natural sea surface films may lead to a significant modification of the static and dynamic surface rheology with further implications to the dynamic exchange processes taking place between sea and atmosphere.

\section{Acknowledgments}

The study was carried out in the framework of scientific activity of the University of Gdansk (supported from DS/ 5200-4-0024-12).

\section{References}

[1] Z. A. Mazurek, J. S. Pogorzelski, and K. Boniewicz-Szmyt, "Evolution of natural sea surface film structure as a tool for organic matter dynamics tracing," Journal of Marine Systems, vol. 74, pp. S52-S64, 2008.

[2] S. J. Pogorzelski and A. D. Kogut, "Structural and thermodynamic signatures of marine microlayer surfactant films," Journal of Sea Research, vol. 49, no. 4, pp. 347-356, 2003.

[3] J. Lucassen, "Dynamic dilational properties of composite surfaces," Colloids and Surfaces, vol. 65, no. 2-3, pp. 139-149, 1992.

[4] Z. Hórvölgyi, M. Máté, A. Dániel, and J. Szalma, "Wetting behaviour of silanized glass microspheres at water-air interfaces: a Wilhelmy film balance study," Colloids and Surfaces A, vol. 156, no. 1-3, pp. 501-507, 1999.

[5] A. W. Adamson and A. Gast, Physical Chemistry of Surfaces, John Wiley \& Sons, New York, NY, USA, 2nd edition, 1997.

[6] E. Kim, D. Kalman, and T. Larson, "Dry deposition of large, airborne particles onto a surrogate surface," Atmospheric Environment, vol. 34, no. 15, pp. 2387-2397, 2000. 
[7] Z. G. Cui, B. P. Binks, and J. H. Clint, "Determination of contact angles on microporous particles using the thin-layer wicking technique," Langmuir, vol. 21, no. 18, pp. 8319-8325, 2005.

[8] A. W. Adamson, Physical Chemistry of Surfaces, John Wiley \& Sons, New York, NY, USA, 8th edition, 1982.

[9] T. Kato, K. Iriyama, and T. Araki, "The time of observation of $\pi$-A isotherms III. Studies on the morphology of arachidic acid monolayers, observed by transmission electron microscopy of replica samples of one-layer Langmuir-Blodgett films using plasma-polymerization," Thin Solid Films, vol. 210-211, no. 1, pp. 79-81, 1992.

[10] F. Ravera, M. Ferrari, E. Santini, and L. Liggieri, "Influence of surface processes on the dilational visco-elasticity of surfactant solutions," Advances in Colloid and Interface Science, vol. 117, no. 1-3, pp. 75-100, 2005.

[11] J. van Hunsel and P. Joos, "Study of the dynamic interfacial tension at the oil/water interface," Colloid \& Polymer Science, vol. 267, no. 11, pp. 1026-1035, 1989.

[12] M. R. Rodríguez Niño, P. J. Wilde, D. C. Clark, and J. M. Rodríguez Patino, "Surface dilational properties of protein and lipid films at the air-water interface," Langmuir, vol. 14, no. 8, pp. 2160-2166, 1998.

[13] Y. Jayalakshmi, L. Ozanne, and D. Langevin, "Viscoelasticity of Surfactant Monolayers," Journal of Colloid And Interface Science, vol. 170, no. 2, pp. 358-366, 1995.

[14] J. H. Clint and S. E. Taylor, "Particle size and interparticle forces of overbased detergents: a Langmuir trough study," Colloids and Surfaces, vol. 65, no. 1, pp. 61-67, 1992.

[15] M. Máté, J. H. Fendler, J. J. Ramsden, J. Szalma, and Z. Hórvölgyi, "Eliminating surface pressure gradient effects in contact angle determination of nano- and microparticles using a film balance," Langmuir, vol. 14, no. 22, pp. 6501-6504, 1998.

[16] B. S. Murray, "Equilibrium and dynamic surface pressurearea measurements on protein films at air-water and oil-water interfaces," Colloids and Surfaces A, vol. 125, no. 1, pp. 73-83, 1997.

[17] M. A. Rodríguez-Valverde, M. A. Cabrerizo-Vílchez, P. Rosales-López, A. Páez-Dueas, and R. Hidalgo-Álvarez, "Contact angle measurements on two (wood and stone) non-ideal surfaces," Colloids and Surfaces A, vol. 206, no. 1-3, pp. 485495, 2002.

[18] C. J. van Oss, R. F. Giese, Z. Li et al., "Determination of contact angles and pore sizes of porous media by column and thin layer wicking," Journal of Adhesion Science and Technology, vol. 6, pp. 413-428, 1992.

[19] W. Wu, R. F. Giese, and C. J. Van Oss, "Change in surface properties of solids caused by grinding," Powder Technology, vol. 89, no. 2, pp. 129-132, 1996.

[20] G. Tolnai, A. Agod, M. Kabai-Faix, A. L. Kovács, J. J. Ramsden, and Z. Hórvölgyi, "Evidence for secondary minimum flocculation of Stöber silica nanoparticles at the air-water interface: film balance investigations and computer simulations," Journal of Physical Chemistry B, vol. 107, no. 40, pp. 11109-11116, 2003.

[21] A. Ulman, An Introduction to Ultrathin Organic Films, Academic Press, Boston, Mass, USA, 1991.

[22] S. Yariv, "Wettability of clay minerals," in Modern Approaches to Wettability: Theory and Applications, M. E. Schrader and G. Loeb, Eds., pp. 279-326, Plenum Press, New York, NY, USA, 1992.

[23] S. Caquineau, A. Gaudichet, L. Gomes, M. C. Magonthier, and B. Chatenet, "Saharan dust: clay ratio as a relevant tracer to assess the origin of soil-derived aerosols," Geophysical Research Letters, vol. 25, no. 7, pp. 983-986, 1998.

[24] A. Avila, I. Queralt-Mitjans, and M. Alarcón, "Mineralogical composition of African dust delivered by red rains over northeastern Spain," Journal of Geophysical Research D, vol. 102, no. 18, pp. 21977-21996, 1997.

[25] J. Keller and R. Lamprecht, "Road dust as an indicator for air pollution transport and deposition: an application of SPOT imagery," Remote Sensing of Environment, vol. 54, no. 1, pp. 1-12, 1995.

[26] H. W. Vallack and D. E. Shillito, "Suggested guidelines for deposited ambient dust," Atmospheric Environment, vol. 32, no. 16, pp. 2737-2744, 1998.

[27] B. Forster, X. Baide, and S. Xingwai, "Modelling suspended particle distribution in near coastal waters using satellite remotely-sensed data," International Journal of Remote Sensing, vol. 15, no. 6, pp. 1207-1219, 1994.

[28] P. Gentien, M. Lunven, M. Lehaître, and J. L. Duvent, "In-situ depth profiling of particle sizes," Deep-Sea Research I, vol. 42, no. 8, pp. 1297-1312, 1995.

[29] S. Chen and D. Eisma, "Fractal geometry of in situ flocs in the estuarine and coastal environments," Netherlands Journal of Sea Research, vol. 32, no. 2, pp. 173-182, 1995.

[30] D. J. Law, A. J. Bale, and S. E. Jones, "Adaptation of focused beam reflectance measurement to in-situ particle sizing in estuaries and coastal waters," Marine Geology, vol. 140, no. 1-2, pp. 47-59, 1997.

[31] R. Arimoto, B. J. Ray, N. F. Lewis, U. Tomza, and R. A. Duce, "Mass-particle size distributions of atmospheric dust and the dry deposition of dust to the remote ocean," Journal of Geophysical Research D, vol. 102, no. 13, pp. 15867-15874, 1997.

[32] S. A. Slinn and W. G. N. Slinn, "Predictions for particle deposition on natural waters," Atmospheric Environment A, vol. 14, no. 9, pp. 1013-1016, 1980.

[33] H. Sievering, "Small-particle dry deposition on natural waters: how large the uncertainty?" Atmospheric Environment, vol. 18, no. 10, pp. 2271-2272, 1984.

[34] W. Alpers and H. Huhnerfuss, "The damping of ocean waves by surface films: a new look at an old problem," Journal of Geophysical Research, vol. 94, pp. 6251-6265, 1989.

[35] G. Franceschetti, A. Iodice, D. Riccio, G. Ruello, and R. Siviero, "SAR raw signal simulation of oil slicks in ocean environments," IEEE Transactions on Geoscience and Remote Sensing, vol. 40, no. 9, pp. 1935-1949, 2002. 

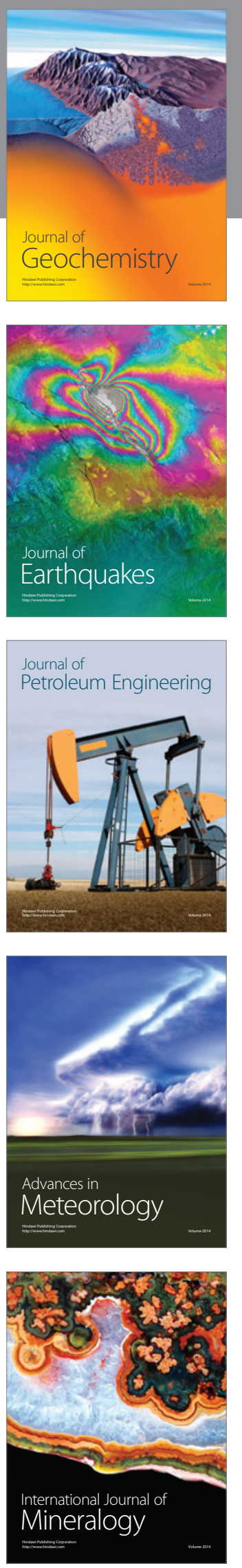
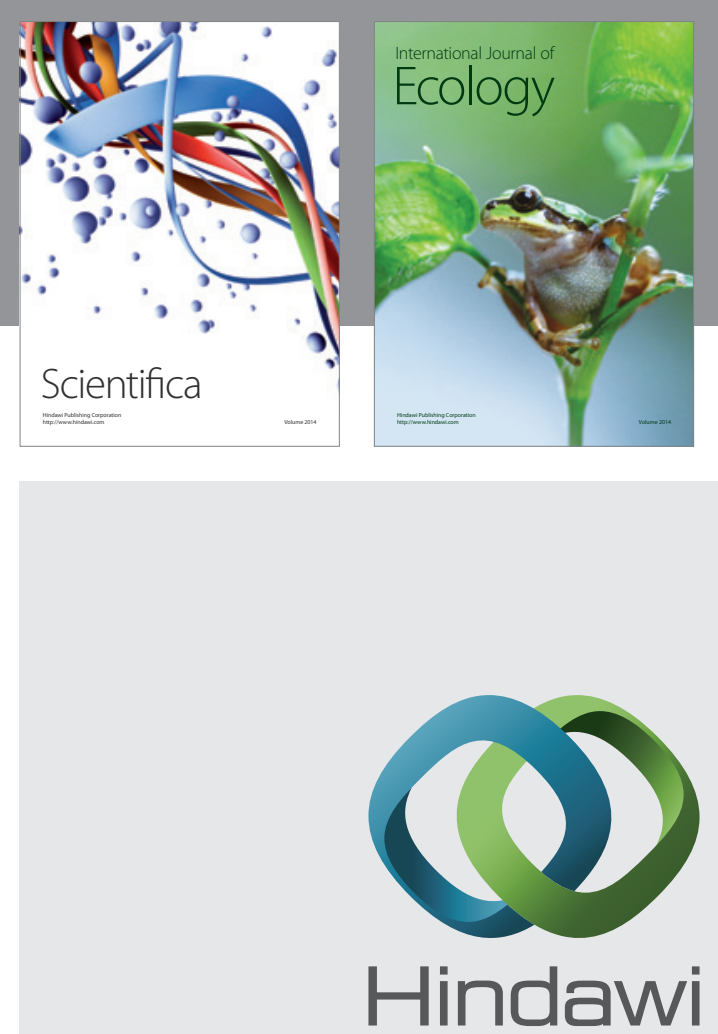

Submit your manuscripts at http://www.hindawi.com
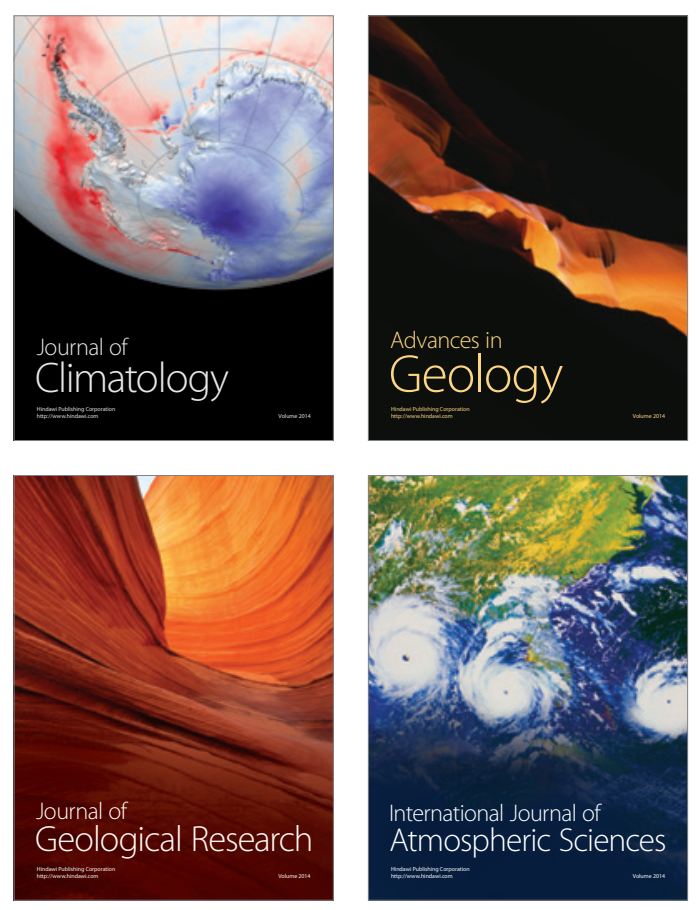
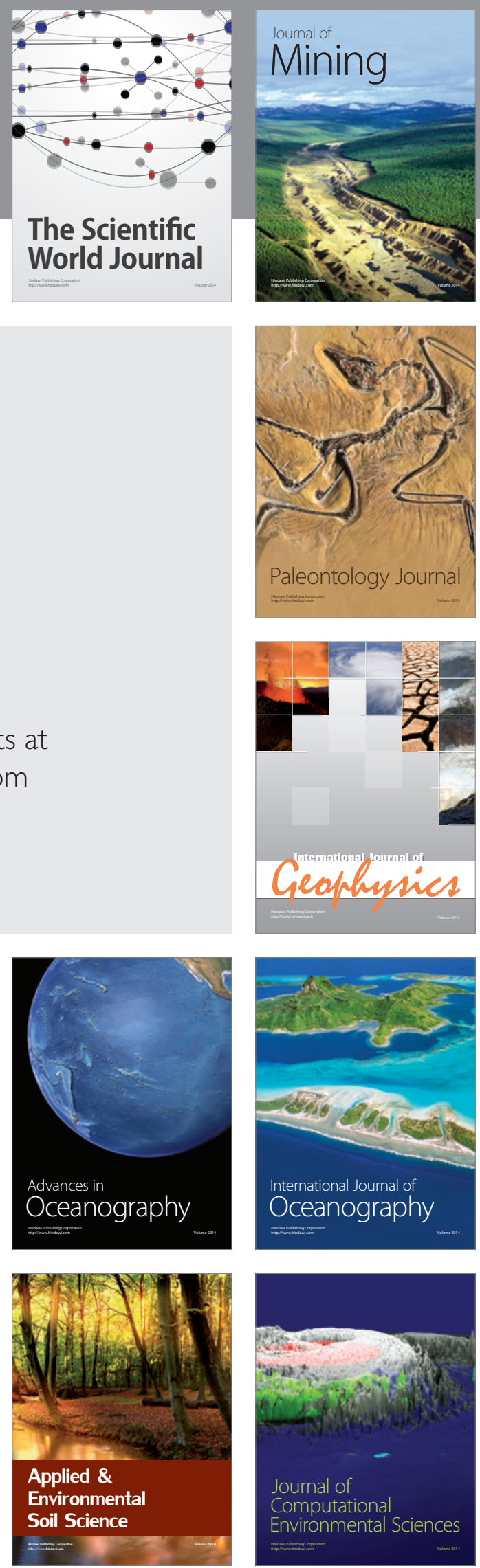